Research article

\title{
Molecular targets for rapid identification of Brucella spp
} Vladyslava G Ratushna ${ }^{1}$, David M Sturgill2 ${ }^{2}$, Sheela Ramamoorthy ${ }^{3}$, Sherry A Reichow ${ }^{3}$, Yongqun $\mathrm{He}^{4}$, Raju Lathigra ${ }^{5}$, Nammalwar Sriranganathan ${ }^{3}$, Shirley M Halling ${ }^{6}$, Stephen M Boyle ${ }^{3}$ and Cynthia J Gibas*1

Address: ${ }^{1}$ Department of Computer Science, College of Information Technology, University of North Carolina at Charlotte, Charlotte, NC, 28223, USA, ${ }^{2}$ Department of Biology, College of Science, Virginia Polytechnic Institute \& State University, Blacksburg, VA, 24061, USA, ${ }^{3 V i r g i n i a-}$ Maryland Regional College of Veterinary Medicine, Virginia Polytechnic Institute \& State University, Blacksburg, VA, 24061, USA, ${ }^{4}$ Unit for Laboratory Animal Medicine, School of Medicine, University of Michigan, Ann Arbor, MI 48105, USA, 5 Walter Reed Army Institute of Research, Department of Bacterial Diseases, Division of Communicable Diseases and Immunology, 503 Robert Grant Avenue, Silver Spring, MD 20910, USA and 'Bacterial Diseases of Livestock Research Unit, United States Department of Agriculture, Agricultural Research Service, National Animal Disease Center, 2300 Dayton Rd, Ames, IA, 50010, USA

Email: Vladyslava G Ratushna - vgratush@uncc.edu; David M Sturgill - davidsturgill@niddk.nih.gov; Sheela Ramamoorthy - sheelar@vt.edu; Sherry A Reichow - Sherry.Reichow@hsi.dhs.gov; Yongqun He - yongqunh@umich.edu; Raju Lathigra - Raju.Lathigra@na.amedd.army.mil; Nammalwar Sriranganathan - nathans@vt.edu; Shirley M Halling - shalling@nadc.ars.usda.gov; Stephen M Boyle - smboyle@vt.edu; Cynthia J Gibas* - cgibas@uncc.edu

* Corresponding author

Published: 22 February 2006

BMC Microbiology2006, 6:13 doi:10.1/86//47|-2/80-6-13
Received: 21 December 2005

Accepted: 22 February 2006

This article is available from: http://www.biomedcentral.com/I47I-2/80/6/13

(c) 2006Ratushna et al; licensee BioMed Central Ltd.

This is an Open Access article distributed under the terms of the Creative Commons Attribution License (http://creativecommons.org/licenses/by/2.0), which permits unrestricted use, distribution, and reproduction in any medium, provided the original work is properly cited.

\begin{abstract}
Background: Brucella is an intracellular pathogen capable of infecting animals and humans. There are six recognized species of Brucella that differ in their host preference. The genomes of the three Brucella species have been recently sequenced. Comparison of the three revealed over $98 \%$ sequence similarity at the protein level and enabled computational identification of common and differentiating genes. We validated these computational predictions and examined the expression patterns of the putative unique and differentiating genes, using genomic and reverse transcription PCR. We then screened a set of differentiating genes against classical Brucella biovars and showed the applicability of these regions in the design of diagnostic tests.

Results: We have identified and tested set of molecular targets that are associated in unique patterns with each of the sequenced Brucella spp. A comprehensive comparison was made among the published genome sequences of $B$. abortus, B. melitensis and B. suis. The comparison confirmed published differences between the three Brucella genomes, and identified subsets of features that were predicted to be of interest in a functional comparison of $B$. melitensis and B. suis to $B$. abortus. Differentiating sequence regions from $B$. abortus, B. melitensis and $B$. suis were used to develop PCR primers to test for the existence and in vitro transcription of these genes in these species. Only B. suis is found to have a significant number of unique genes, but combinations of genes and regions that exist in only two out of three genomes and are therefore useful for diagnostics were identified and confirmed.

Conclusion: Although not all of the differentiating genes identified were transcribed under steady state conditions, a group of genes sufficient to discriminate unambiguously between $B$. suis, B. melitensis, and $B$. abortus was identified. We present an overview of these genomic differences and the use of these features to discriminate among a number of Brucella biovars.
\end{abstract}




\section{Background}

Brucella is a facultative intracellular pathogen that causes abortion in cattle, goats and sheep and a febrile illness ("undulant fever") in humans. Animal brucellosis is a serious problem worldwide and is endemic globally. In areas where it is endemic, human brucellosis is quite common but often not diagnosed. There are six recognized Brucella species that differ in their preference for certain hosts. B. abortus preferentially infects cattle, B. melitensis infects sheep and goats, and $B$. suis infects pigs. All three of these species, as well as B. canis, can infect humans, and $B$. melitensis is associated with the most serious human infections $[1,2]$. The brucellae are grouped with the $\alpha$-proteobacteria and are related to other cell-associated parasites of plants and animals. The classical Brucella taxonomy is based on six species (B. melitensis, B. abortus, $B$. suis, B. neotomae, B. ovis and B. canis) characterized by their host preferences. Later observations of high homology from DNA-DNA hybridization studies led many to adopt a monospecific system [3,4]. The Subcommittee on the Taxonomy of Brucella also accepted this classification in 1986, along with the caveat that the classical species names should be used "to avoid confusion." Most researchers still prefer to use the species system, which recently has been given more credence by detailed biochemical and genetic studies [5].

Macrophages are among the first targets of Brucella invasion, and the bacteria can survive within this naturally hostile intracellular environment [6]. Macrophages are important in transporting Brucella to tissues throughout the host, where they can survive in a variety of cell types [7]. Several studies have suggested that Brucella delays phagolysosomal fusion as a survival mechanism in macrophages, while in non-professional phagocytes Brucella appears to modulate the interior of the phagosome and evades intracellular degradation by avoiding the endocytic/phagocytic cascade [8]. It is not known definitively where Brucella replicates within the vertebrate cell. Observations have suggested that Brucella replicates within the rough endoplasmic reticulum (ER) in several cell types, including trophoblasts [9] and Vero cells [10]. It has been shown that lipid raft-associated molecules, such as glycophosphatidylinositol anchored molecules, play a role in determining the intracellular fate of Brucella [11]. Studies identifying ER markers on Brucella-containing compartments have also supported the theory of the ER as the site of replication [8]. The detailed mechanism of Brucella intracellular survival is not well understood and is assumed related to patterns of gene expression in both the pathogen and host. For example, most Brucella spp. are smooth due to expression of $\mathrm{O}$-side chain genes, replicate inside macrophages and are virulent. In contrast, $B$. canis is rough, yet still capable of macrophage survival and is also virulent $[12,13]$. In the interest of developing a DNA microarray optimized for comparative study of the brucellae, we have carried out a three-way genome comparison of $B$. suis [14], B. melitensis [15], and draft B. abortus [16] sequences, at both the nucleotide and predicted coding sequence (CDS) levels. B. melitensis, B. suis, and B. abortus each have approximately $3 \mathrm{Mb}$ of genomic DNA, divided into a large chromosome of approximately $2 \mathrm{Mb}$ and a small chromosome of approximately $1 \mathrm{Mb}$. We found that over 3100 genes identified in B. suis or B. melitensis appear to have a homolog in both of these genomes and also in B. abortus. Fewer than 100 genes were identified as present in only one or two of the three genomes, with an additional group of close to 100 genes having significant deletions in one or two of the genomes relative to the others. Annotated or predicted genomic sequence features that appear to distinguish the three species were probed using PCR and RT-PCR, to verify their uniqueness and to test for transcription under in vitro growth conditions. PCR primers were then used to assay and classify several variant strains. Differentiating genes will provide targets for rapid discrimination among Brucella species, as probes on a diagnostic chip, and will also be useful for elucidation of differences in host preference and mechanism of virulence among these closely related species.

\section{Results and discussion Three-way genome comparison}

The genomes of the three sequenced Brucella biovars ( $B$. abortus 9-941, B. melitensis $16 \mathrm{M}$ and B. suis 1330) were compared globally to identify the extent of similarity between these closely related bacterial species.

Our results for comparison of B. suis to B. melitensis (Figure $1 \mathrm{~A}$ ) were generally in agreement with those of Paulsen et al., 2002 [14]. We further tried to pinpoint which of the potentially unique genes could also distinguish $B$. melitensis and $B$. suis from $B$. abortus, and would therefore be of interest as differentiating probes on an expression array, by including draft genome sequence from $B$. abortus in the comparison. Subsequent results of comparisons to the finished $B$. abortus sequence by Halling et al. [16], are in reasonable agreement with our results, though some minor differences in feature identification arose from our use of a draft annotation. Our computational and experimental analysis identified and confirmed a set of 22 ORFs to be present in $B$. suis 1330 , but not in B. melitensis $16 \mathrm{M}$ or $B$. abortus 9-941, and another 22 ORFs found in both $B$. suis 1330 and $B$. abortus 9-941, but not in B. melitensis 16 $M$. These differentiating ORFs extend a known set of 217 ORFs, which have been shown experimentally to differ in expression between the Brucella species in a B. melitensis $16 \mathrm{M}$ based microarray experiment [17]. Our three-way genomic comparison together with the genomic comparison performed by Halling et al. [16], demonstrates that $B$. suis 1330 and $B$. abortus 9-941 both contain the ORFs 

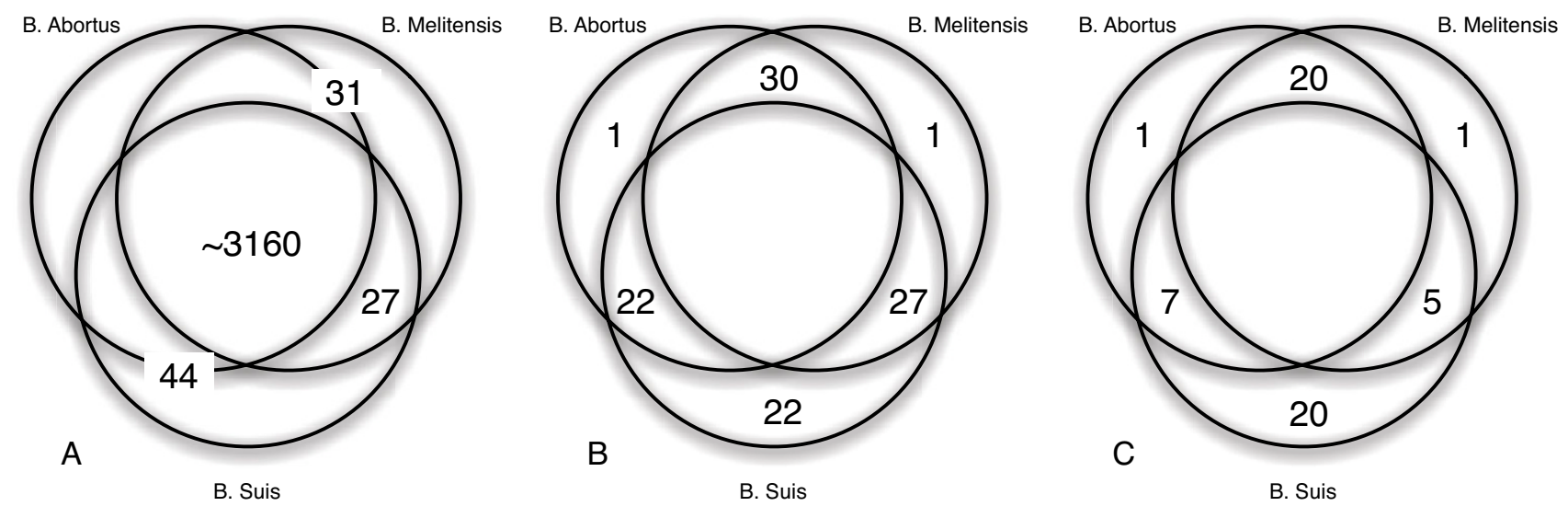

Figure I

Distribution of differentiating genes in three Brucella sequences. The figure contains Venn diagrams, showing the distribution of differentiating genes in the three Brucella genomes: A) predicted from whole-genome sequence comparison of $B$. melitensis $16 \mathrm{M}$ and $B$. suis I 330 with additional publicly available sequence from B. abortus $9-94$ I B) confirmed by genomic PCR analysis and $C$ ) shown to be transcribed by RT-PCR analysis

identical to BMEI1747, BMEII1071, BMEI 1746, and BMEI1896, BMEI1919-21, BMEI1923, BMEII0826, BMEII0850, and BMEI1662, which were shown to be completely or partially missing from either B. suis S100 or B. abortus S2308 or both respectively [17].

Supporting previous findings that the three genomes are highly similar, the majority (>90\%) of annotated genes were found to share $98-100 \%$ sequence identity at the nucleotide level with their apparent homologues in each of the other genomes. The majority of differentiating genes identified are in large $(\sim 20 \mathrm{~kb})$ regions, which partly account for differences in chromosome size. Most of these genes have functional assignments in existing annotation. Table 1 provides a detailed description of the differentiating genes identified in this study, organized according to their order in the B. suis genome, or in the B. melitensis genome in those cases where there was no $B$. suis sequence match. Genes shown as present in B. suis and B. melitensis but absent in $B$. abortus mainly correspond to a large deletion in the genome sequence of $B$. abortus relative to the other genomes, which was previously identified by Vizcaino and colleagues [18], and identifiable in [GenBank:AF076290]. The identities of these genes were confirmed by comparison of that record to the draft $B$. abortus sequence.

\section{Functional significance of genomic differences}

We identified several multi-gene regions that contain the majority of differentiating genes (Table 2). These six regions alone are sufficient to discriminate between the three Brucella species. In a pairwise comparison, thirtythree regions were described as unique to either $B$. suis or
B. melitensis [14]. In a three-way comparison that included the draft $B$. abortus sequence, we find that many of these differentiating features can no longer be considered unique for the purpose of discriminating among the three species. Fewer single-species specific genes remain, twenty-two unique genes in B. suis and one in B. melitensis, which demonstrates the homogeneity of the genus. A complete list of differentiating coding regions is given in Table 1, and their possible significance is described below.

\section{Metabolism}

Several CDSs homologous to components of an amino acid ABC transport system were found in B. abortus and $B$. suis but were absent in $B$. melitensis. This may indicate that $B$. abortus and $B$. suis have the ability to utilize a nutrient that $B$. melitensis does not. Different patterns of amino acid utilization are used to distinguish among the brucellae [19], and variations in amino acid transporter content are consistent with the observation that each species has a distinct pattern of nutrient utilization. Most of these genes are present on the differentiating region SA2 (Table 2), suggesting that the acquisition or loss of this region could have been related to a change in environment or nutrient availability for the ancestral species. Two ABC transporter permeases (BR0952/BR0953) unique to B. suis were also identified. Transcription of these genes in $B$. suis was detected by RT-PCR (Table 3).

\section{Virulence}

A detailed analysis of a $50 \mathrm{~kb}$ region (BRA1072-1116/ BMEII0183-227) was performed to complement our general comparison of gene content. This $50 \mathrm{~kb}$ region resides on Chromosome II of each Brucella species and may rep- 


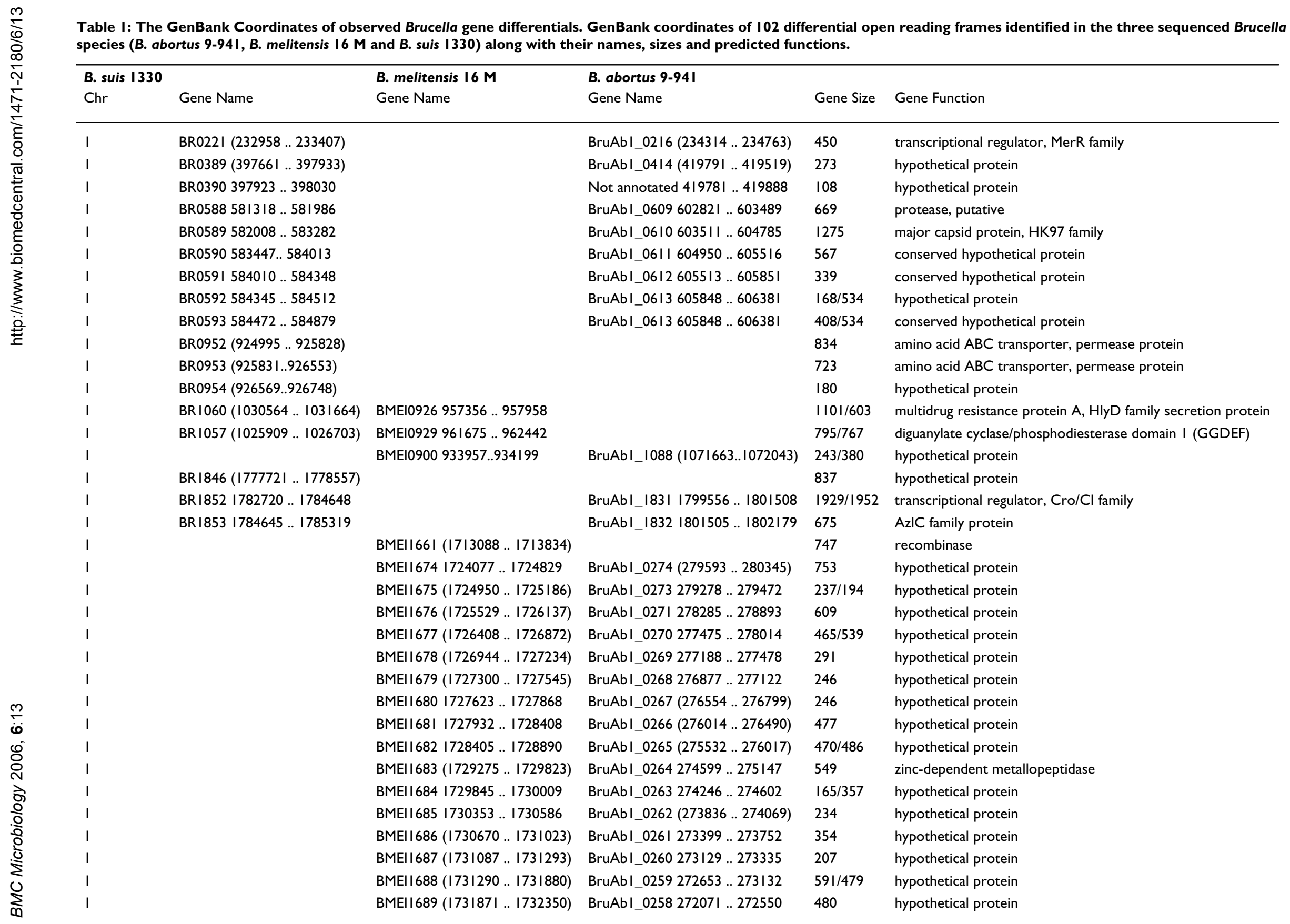


I: The GenBank Coordinates of observed Brucella gene differentials. GenBank coordinates of 102 differential open readin (B. abortus 9-94I, B. melitensis 16 M and B. suis I330) along with their names, sizes and predicted functions. (Continued)

BMEII690 (I732392 .. 1732697) BruAbI_0257 27I724 .272029

BMEII69I (I732898 .. I734790) BruAbI_0256 269642 .. 27I523

BMElI692 (I734940 .. I736856) BruAbI_0255 267576 .. 269492

BMEII693 (I737057 .. 1737266) BruAbI_0254 267166 .. 267375

BMEII694 (I737368 .. 1738384) BruAbI_0253 266048 .. 267064

BMEII695 (I738538 .. 1739I55) BruAbI_0252 265457 .. 265894

BMEII696 (I739I25 .. 1740654) BruAbI_025I 263780 .. 265308

BMEII697 (I74065I .. I74I532) BruAbI_0250 262902..263783

BMEII 698 (I74I529 .. I74I843) BruAbI_0249 26259I .. 262905

BMEII 699 (I74I840 .. 1742049) BruAbI_0248 262385 .. 262594

BMEII 700 (I742050 .. 1742268) BruAbI_0247 262I66 .. 262384

BMEII70I I742369 .. 174264I BruAbI_0246 26I652 .. 262098

BMEII 702 (I742779 .. 1743975) BruAbI_0245 260459 .. 261655

BRA0227 (214967 .. 215674)

BRA0362 343695 .. 344903

BRA0363 345I88 .. 3454I8

BRA0364 345499 .. 346557

BRA0365 (347606 .. 347932)

BRA0366 (347935 .. 349578)

BRA0367 (34958I .. 349763)

BRA0368 (349766 .. 350557)

BRA0369 350655 .. 350807

BRA0370 (350825 .. 351049)

BRA037I (35I052 .. 35I270)

BRA0372 351940 .. 352320

BRA0373 352317 .. 354269

BRA0374 (354676 .. 356100)

BRA0375 (356254 .. 357279)

BRA0376 (3573I 3 .. 358038)

BRA0377 (3582I7 .. 359938)

BRA0378 (360I80 .. 361004)

BRA0379 (36II49 .. 36|343)

BRA04I 8 (402846 .. 403826)

BRA04I 9 (4038I0 .. 404880)

BRA0420 405I 44 .. 406394

BRA042I 4064I5 .. 407650

BRA0422 407647 .. 408843

BRA0423 (4089/4 .. 409636)

\section{BMEIII 0161054886 .. 1055593}

BMEII0849 885138 .. 885878

BMEII0848 884084 .. 885I54

BMEII0847 (882570 .. 883886)

BMEII0846 (88I3। 4 .. 882537)

BMEII0844 879463 .. 880I22
BMEII0845 (880193 .. 881317)

$\begin{array}{ll}306 & \text { hypothetical protein } \\ 1893 / 1887 & \text { hypothetical membrane spanning protein } \\ 1917 & \text { flagellar protein FIg } \\ 210 & \text { hypothetical protein } \\ 1017 & \text { hypothetical protein } \\ 618 / 438 & \text { hypothetical protein } \\ 1530 / 1529 & \text { hypothetical membrane spanning protein } \\ 882 & \text { virulence-associated protein E } \\ 315 & \text { hypothetical protein } \\ 210 & \text { hypothetical protein } \\ 219 & \text { hypothetical protein } \\ 262 / 446 & \text { hypothetical protein } \\ 1197 & \text { transposase } \\ 708 & \text { protease I } \\ 1209 & \text { site-specific recombinase, phage integrase family } \\ 231 & \text { DNA-binding protein, putative } \\ 1059 & \text { RepA-related protein } \\ 327 & \text { hypothetical protein } \\ 1644 & \text { TrbL protein } \\ 183 & \text { hypothetical protein } \\ 792 & \text { TrbJ protein } \\ 153 & \text { hypothetical protein } \\ 225 & \text { hypothetical protein } \\ 219 & \text { TraC protein } \\ 381 & \text { TraJ protein } \\ 953 & \text { Tral protein, putative } \\ 1425 & \text { hypothetical protein } \\ 1026 & \text { hypothetical protein } \\ 726 & \text { hypothetical protein } \\ 1722 & \text { conserved hypothetical protein } \\ 825 & \text { hypothetical protein } \\ 195 & \text { DNA-damage-inducible protein J, putative } \\ 981 / 740 & \text { GDP-4-dehydro-d-rhamnose reductase } \\ 1071 & \text { GDP-mannose 4,6-dehydratase } \\ 1250 / 1317 & \text { glycosyltransferase } \\ 1236 / 1224 & \text { glycosyltransferase, group I family protein } \\ 1197 / I I 25 & \text { lipopolysaccharide n-acetylglucosaminyltransferase } \\ 723 / 660 & \text { outer membrane protein, 3I kDa Found in } B . \text { neotomae } \\ & \end{array}$


Table I: The GenBank Coordinates of observed Brucella gene differentials. GenBank coordinates of I02 differential open reading frames identified in the three sequenced Brucella species (B. abortus 9-94 I, B. melitensis $16 \mathrm{M}$ and B. suis 1330) along with their names, sizes and predicted functions. (Continued)

\begin{tabular}{|c|c|c|c|c|c|}
\hline 2 & BRA0424 (4I0033 .. 4I0647) & BMEII0843 878500 .. 879003 & & $615 / 504$ & acetyltransferase, CysE/LacA/LpxA/NodL family \\
\hline 2 & BRA0425 (4I0659 .. 4II92I) & BMEII0842 877II 5 .. 878377 & & 1263 & hypothetical protein \\
\hline 2 & BRA0426 (4II9|8 .. 4I2535) & BMEII084I 876576 .. 877।I8 & & $618 / 543$ & hypothetical protein \\
\hline 2 & BRA0427 (4I2532 .. 4|34|3) & BMEII0840 875548 .. 876504 & & $882 / 957$ & glycosyltransferase involved in cell wall biogenesis \\
\hline 2 & BRA0428 (4I34I0 .. 4|4537) & BMEII0839 874562 .. 875626 & & $1128 / 1065$ & undecaprenyl-phosphate $\alpha$-n-acetylglucosaminyl transferase \\
\hline 2 & BRA0429 4I4830 .. 4I6323 & BMEII0838 (8727I 9 .. 874224) & & $1494 / 1506$ & succinoglycan biosynthesis transport protein exot \\
\hline 2 & BRA0430 4I6339 .. 417352 & BMEII0837 (87I690 .. 872703) & & 1014 & glycosyltransferase, group 2 family protein \\
\hline 2 & BRA043I (4I7308 .. 4I8549) & BMEII0836 870493 .. 87I734 & & 1242 & dTDP-4-dehydrorhamnose 3,5-epimerase \\
\hline 2 & BRA0432 4I8666 .. 420045 & BMEII0835 (868997 .. 869920) & & $1380 / 924$ & glycosyltransferase, group I family protein \\
\hline 2 & BRA0433 $420083 . .42 \mid 444$ & BMEII0834 (867598 .. 868959) & & 1362 & glutamate-I-semialdehyde 2, I-aminomutase \\
\hline 2 & BRA0434 421423 .. 422757 & BMEII0833 (866285 .. 867619) & & 1335 & conserved hypothetical protein \\
\hline 2 & BRA0435 422878 .. 423939 & BMEII0832 (865I03 .. 866I70) & & $1062 / 1068$ & UDP-glucose 4-epimerase \\
\hline 2 & BRA0436 423939 .. 42529I & BMEII083I (86375I .. 865064) & & $1353 / 1314$ & conserved hypothetical protein \\
\hline 2 & BRA0437 (425254 .. 425778) & BMEII0830 863234 .. 863788 & & $525 / 555$ & dTDP-4-dehydrorhamnose 3,5-epimerase \\
\hline 2 & BRA0438 426099 .. 427400 & BMEII0829 (862282 .. 862944) & & $1302 / 663$ & methyltransferase, putative \\
\hline 2 & BRA0438 426099 .. 427400 & BMEII0828 (861644 .. 862210) & & $1302 / 567$ & possible S-adenosylmethionine-dependent methyltransferase \\
\hline 2 & BRA0439 $427403 . .428212$ & BMEII0827 (860832 .. 861719) & & 480 & glucose-I-phosphate cytidylyltransferase \\
\hline 2 & BRA054I (52I842 .. 522066) & & BruAb2_068I $692179 . .692403$ & 225 & hypothetical protein \\
\hline 2 & BRA0630 (610688 .. 611938) & & BruAb2_0596 605I52.. 606402 & $|25|$ & amino acid dehydrogenase, putative \\
\hline 2 & BRA063I (612027 .. 612788) & & BruAb2_0595 604302.605063 & 762 & amino acid $A B C$ transporter \\
\hline 2 & BRA0632 (612944 .. 6137|7) & & BruAb2_0594 $603373 . .604146$ & 774 & amino acid $A B C$ transporter, \\
\hline 2 & BRA0633 (613902 .. 615005) & & BruAb2_0593 602085.603188 & 1104 & conserved hypothetical protein \\
\hline 2 & BRA0634 615107 .. 615556 & & BruAb2_0592 (601534 .. 601982) & 450 & transcriptional regulator, AsnC family \\
\hline 2 & BRA0635 615836 .. 617563 & & BruAb2_059I (599527 .. 60I254) & 1728 & twin-arginine translocation signal domain protein \\
\hline 2 & BRA0636 (617674 .. 618876) & & BruAb2_0590 598292.599416 & $1203 / 1125$ & beta-ketoadipyl CoA thiolase \\
\hline 2 & BRA0749 731323 .. 732192 & & BruAb2_0483 (484959 .. 485828) & 870 & sugar $A B C$ transporter, permease protein, putative \\
\hline 2 & BRA0907 888804 .. 890204 & & BruAb2_0326 (3269II .. 32831I) & $140 \mid$ & conserved hypothetical protein \\
\hline 2 & BRAI096 $1082617 \ldots 1083330$ & & BruAb2_1035 1037839 .. 1038552 & 714 & transcriptional regulator, putative \\
\hline 2 & BRA0553 (532630 .. 534594) & BMEII07I7 755374 .. 757398 & & $1965 / 2025$ & hemagglutinin, cell wall surface protein, putative \\
\hline
\end{tabular}


Table 2: Summary of RT-PCR results from differentiating CDSs Brucella species, grouped by differentiating island. Transcripts detected in each differentiating sequence island of B. abortus 9-94I, B. melitensis $16 \mathrm{M}$ and $B$. suis 1330 , when the cell cultures were grown at $37^{\circ} \mathrm{C}$ for 36 hours in trypticase soy broth (Difco).

\begin{tabular}{|c|c|c|c|c|c|c|c|}
\hline \multirow[b]{2}{*}{ Location } & \multicolumn{3}{|c|}{ B. suis } & \multicolumn{3}{|c|}{ B. melitensis } & \multirow{2}{*}{$\begin{array}{l}\text { B. abortus } \\
\text { Observed }\end{array}$} \\
\hline & Predicted & Observed & No Band & Predicted & Observed & No Band & \\
\hline B. suis Chr. I (SI) & 4 & 4 & - & 1 & I & - & - \\
\hline B. suis Chr. II (S2) & 18 & 17 & 1 & - & - & - & - \\
\hline B. melitensis Chr. I (MI) & - & - & - & 1 & I & - & - \\
\hline B. abortus Chr. I (AI) & - & - & - & - & - & - & 1 \\
\hline B. suis + B. melitensis Chr. I (SMI) & I & I & - & 2 & 2 & - & - \\
\hline B. suis + B. melitensis Chr. II (SM2) & 25 & 16 & 9 & 24 & 6 & 18 & - \\
\hline B. suis + B. abortus Chr. I (SAI) & 11 & 3 & 8 & - & - & - & 7 \\
\hline B. suis + B. abortus Chr. II (SA2) & 11 & 7 & 4 & - & - & - & 6 \\
\hline B. melitensis + B. abortus Chr. I (MAI) & - & - & - & 30 & 21 & 9 & 23 \\
\hline
\end{tabular}

resent a composite transposon [14]. It is flanked with insertion sequences that suggest a foreign origin, although its $\mathrm{G}+\mathrm{C}$ content $(56.8 \%)$ is close to the Brucella average. Although this island does not contain obvious virulence genes, it includes a large number of peptide ABC transporter genes. In some pathogens, autotransporter proteins have been implicated as virulence determinants [20]; whether this is the case for the brucellae has not been reported as yet.

Comparison with $B$. suis shows that this region is also present in B. melitensis and B. abortus (Bricker, Acc. No. AF454951) but contains deletions in the dipeptide ABC transporter permease protein gene, the 3-hydroxyacylCoA dehydrogenase family protein gene, and a transcriptional regulator. Each of these small deletions is in-frame, but result in missing amino acids and potentially in altered function, perhaps explaining significant metabolic differences between the three species.

A $25 \mathrm{~kb}$ region present only in B. suis and B. melitensis was revealed by three-way comparison to be a differentiating feature. This region, absent only in B. abortus (region MS2, Table 2), contains five glycosyl transferases (BMEII0835/ 0837/0840/0845-0847; BRA0420-0422/0427/0430/ 0432) and a succinoglycan biosynthesis transport protein (BMEII0838/BRA0429). However, no transcription of succinoglycan biosynthesis transport protein was detected by RT-PCR for either species. In B. melitensis, transcription of four out of five glycosyl transferases was detected by RTPCR, while in B. suis transcription of only one of these genes was observed. These genes may be important in $\mathrm{O}-$ side chain biosynthesis - one of the known virulence determinants of Brucella [21]. This region also contains several uncharacterized genes that may be novel virulence factors, including a putative outer membrane protein and several conserved hypothetical proteins. This region was shown to be present in B. melitensis, B. suis, B. ovis, B. canis, and B. neotomae, but not in B. abortus [18]. Vizcaino et al. conjecture that this region is absent due to a deletion event before the differentiation of this species and its biovars, since none of the $B$. abortus biovars possess this region. The deletion of this island may have impacted the host range of $B$. abortus and pushed its divergence from the Brucella ancestor.

A three-way comparison also reveals species-specific differences in two gene clusters of urease subunits present on Chromosome II of B. suis, B. abortus, and B. melitensis (ureA-G-1 BR0267-BR0273 and ureA-G-2 BR1356BR1362 in B. suis). Some subunits of these clusters are conserved among other bacterial species, and ureases have been shown to be important to virulence in several animal models of bacterial infection [22]. B. melitensis has a $1 \mathrm{bp}$ insertion in ureA-1 (BR0268), representing a potential frame shift. A 6 bp insertion in the ureD-2 (BR1362) gene of $B$. abortus was identified, within overlapping segments of a highly repetitive region of the gene. In the ure $\mathrm{E}-2$ gene (BR1359) of B. abortus two separate single base deletions are present, possibly shifting the frame of translation. Finally, the last 22 bp of ureE-1 (BR0271) were shown to be $100 \%$ identical in B. abortus and B. melitensis but significantly diverged in $B$. suis, including a 2 bp deletion. This variation within these urease gene clusters could prove to be significant to virulence differences.

\section{Secretion systems}

Our analysis revealed a cluster of transfer genes (tra/trb) unique to $B$. suis and potentially significant to secretion (region S2, Table 2). Transcription of all but one gene in this island was observed by RT-PCR. Several genes in this region (trbL, trbJ, traC, traJ, traI, and repA) are homologous to genes involved in mating pair formation described for Escherichia coli plasmid RP4 [23], to receptor complex formation in bacteriophage-host gene transfer systems [24], and to genes of type IV secretion systems of other species 
Table 3: Detailed results for RT-PCR analysis of differentiating CDSs from Brucella species, by gene. Detailed breakdown of the transcripts detected in each differentiating sequence island of B. abortus $9-941$, B. melitensis $16 \mathrm{M}$ and B. suis 1330, when the cell cultures were grown at $37^{\circ} \mathrm{C}$ for 36 hours in trypticase soy broth (Difco).

\begin{tabular}{|c|c|c|c|c|c|c|c|c|c|}
\hline \multirow[b]{2}{*}{ \# } & \multirow{3}{*}{$\begin{array}{l}\text { CDS Name } \\
\text { B. suis Chromosome I (SI) }\end{array}$} & \multirow{3}{*}{ Function } & \multirow{3}{*}{$\begin{array}{l}\text { Amplicon } \\
\text { Size (bp) }\end{array}$} & \multicolumn{2}{|c|}{ B. suis } & \multicolumn{2}{|c|}{ B. melitensis } & \multicolumn{2}{|c|}{ B. abortus } \\
\hline & & & & Predicted & Observed & Predicted & Observed & Predicted & Observed \\
\hline A. & & & & & & & & & \\
\hline I & BR0952 & putative amino acid $A B C$ transporter, permease protein & 396 & + & + & - & - & - & - \\
\hline 2 & BR0953 & putative amino acid $A B C$ transporter, permease protein & 438 & + & + & - & - & - & - \\
\hline 3 & BR0954 & hypothetical protein & 153 & + & + & - & - & - & - \\
\hline 4 & BRI846 & hypothetical protein & $\begin{array}{l}721^{S} \\
469^{M}\end{array}$ & + & + & + & + & - & - \\
\hline
\end{tabular}

B. B. suis Chromosome II (S2)

\begin{tabular}{|c|c|c|c|c|c|c|c|c|c|}
\hline 5 & BRA0362 & putative site-specific recombinase, phage integrase family & 722 & + & + & - & - & - & - \\
\hline 6 & BRA0363 & putative DNA-binding protein & 148 & + & + & - & - & - & - \\
\hline 7 & BRA0364 & putative RepA-related protein & 655 & + & + & - & - & - & - \\
\hline 8 & BRA0365 & hypothetical protein & 167 & + & + & - & - & - & - \\
\hline 9 & BRA0366 & putative TrbL protein & 170 & + & + & - & - & - & - \\
\hline 10 & BRA0367 & putative TrbL protein & 119 & + & + & - & - & - & - \\
\hline 11 & BRA0368 & putative TrbJ protein & 354 & + & + & - & - & - & - \\
\hline 12 & BRA0369 & hypothetical protein & 123 & + & + & - & - & - & - \\
\hline 13 & BRA0370 & hypothetical protein & 121 & + & + & - & - & - & - \\
\hline 14 & BRA037I & putative $\mathrm{TraC}$ protein & 140 & + & + & - & - & - & - \\
\hline 15 & BRA0372 & putative Tral protein & 218 & + & + & - & - & - & - \\
\hline 16 & BRA0373 & putative Tral protein & 173 & + & - & - & - & - & - \\
\hline 17 & BRA0374 & hypothetical protein & 768 & + & + & - & - & - & - \\
\hline 18 & BRA0375 & hypothetical protein & 648 & + & + & - & - & - & - \\
\hline 19 & BRA0376 & hypothetical protein & 532 & + & + & - & - & - & - \\
\hline 20 & BRA0377 & conserved hypothetical protein & 867 & + & + & - & - & - & - \\
\hline 21 & BRA0378 & hypothetical protein & 191 & + & + & - & - & - & - \\
\hline 22 & BRA0379 & putative DNA-damage-inducible protein J & 119 & + & + & - & - & - & - \\
\hline C. & \multicolumn{9}{|c|}{ B. melitensis Chromosome I (MI) } \\
\hline 23 & BMEII66I & recombinase & 218 & - & - & + & + & - & - \\
\hline D. & B. abortus & & & & & & & & \\
\hline 24 & $\begin{array}{l}6 \mathrm{~kb} \text { Partial differential, } \\
\text { primer pair I }\end{array}$ & & 782 & - & - & - & - & + & + \\
\hline
\end{tabular}


Table 3: Detailed results for RT-PCR analysis of differentiating CDSs from Brucella species, by gene. Detailed breakdown of the transcripts detected in each differentiating sequence island of B. abortus $9-94 \mathrm{I}$, B. melitensis $16 \mathrm{M}$ and B. suis 1330 , when the cell cultures were grown at $37^{\circ} \mathrm{C}$ for 36 hours in trypticase soy broth (Difco). (Continued)



E. B. suis and B. melitensis Chromosome I (SMI)

\begin{tabular}{|c|c|c|c|c|c|c|c|c|c|}
\hline 26 & BRI060/BMEI0926/ & $\begin{array}{l}\text { putative } \mathrm{HlyD} \text { family secretion protein/multidrug resistance } \\
\text { protein } \mathrm{A}\end{array}$ & 207 & - & - & + & + & - & - \\
\hline 27 & BRI057/BMEI0929 & $\begin{array}{l}\text { Diguanylate cyclase/phosphodiesterase domain/putative } \\
\text { GGDEF domain protein }\end{array}$ & 323 & + & + & + & + & - & - \\
\hline
\end{tabular}

F. B. suis and B. melitensis Chromosome II (SM2)

\begin{tabular}{|c|c|c|c|c|c|c|c|c|c|}
\hline 28 & BRA0227/BMEIII016 & putative Thil/Pfpl family protein/protease I & 466 & + & + & + & - & - & - \\
\hline 29 & BRA04 I8/BMEII0849 & $\begin{array}{l}\text { putative fucose synthetase family protein/GDP-4-dehydro-D- } \\
\text { rhamnose reductase }\end{array}$ & 363 & + & + & + & - & - & - \\
\hline 30 & BRA04I9/BMEII0848 & $\begin{array}{l}\text { putative GDP-mannose 4,6-dehydratase Bme9/GDP-mannose } \\
4,6 \text {-dehydratase }\end{array}$ & 239 & + & - & + & + & - & - \\
\hline 31 & BRA0420/BMEII0847 & putative glycosyltransferase/glycosyl transferase & 657 & + & + & + & - & - & - \\
\hline 32 & BRA042I/BMEII0846 & $\begin{array}{l}\text { putative glycosyltransferase, group I family protein/glycosyl } \\
\text { transferase }\end{array}$ & 229 & + & - & + & - & - & - \\
\hline 33 & BRA0422/BMEII0845 & $\begin{array}{l}\text { putative glycosyltransferase, group I family protein/: } \\
\text { lipopolysaccharide } \mathrm{N} \text {-acetylglucosaminyltransferase }\end{array}$ & $\begin{array}{l}470^{S} \\
398^{M}\end{array}$ & + & + & + & - & - & - \\
\hline 34 & BRA0423/BMEII0844 & $\begin{array}{l}\text { putative outer membrane protein, } 31 \mathrm{kDa} / 3 \mathrm{l} \mathrm{kDa} \text { outer- } \\
\text { membrane immunogenic protein precursor }\end{array}$ & 317 & + & + & + & + & - & - \\
\hline 35 & BRA0424/BMEII0843 & $\begin{array}{l}\text { putative acetyltransferase, CysE/LacA/LpxA/NodL family/ } \\
\text { putative colanic acid biosynthesis acetyltransferase WCAF }\end{array}$ & 366 & + & - & + & - & - & - \\
\hline 36 & BRA0425/BMEII0842 & putative membrane protein Bme3/hypothetical protein & 774 & + & - & + & - & - & - \\
\hline 37 & BRA0426/BMEII084I & putative Bme2 protein/hypothetical protein & 286 & + & - & + & + & - & - \\
\hline 38 & BRA0427/BMEII0840 & $\begin{array}{l}\text { putative glycosyl transferase, group } 2 \text { family protein/ } \\
\text { glycosyltransferase involved in cell wall biogenesis }\end{array}$ & 279 & + & + & - & - & - & - \\
\hline 39 & BRA0428/BMEII0839 & $\begin{array}{l}\text { putative undecaprenyl-phosphate alpha- } \mathrm{N} \text { - } \\
\text { acetylglucosaminyltransferase }\end{array}$ & 672 & + & + & + & - & - & - \\
\hline 40 & BRA0429/BMEII0838 & $\begin{array}{l}\text { putative polysaccharide biosynthesis protein/succinoglycan } \\
\text { biosynthesis transport protein exot }\end{array}$ & 306 & + & - & + & - & - & - \\
\hline 41 & BRA0430/BMEII0837 & $\begin{array}{l}\text { putative glycosyltransferase, group } 2 \text { family protein/ } \\
\text { glycosyltransferase }\end{array}$ & 488 & + & - & + & - & - & - \\
\hline 42 & BRA043I/BMEII0836 & $\begin{array}{l}\text { conserved hypothetical protein/dTDP-4-dehydrorhamnose } \\
\text { 3,5-epimerase }\end{array}$ & 281 & + & - & + & - & - & - \\
\hline 43 & BRA0432/BMEII0835 & $\begin{array}{l}\text { putative glycosyltransferase, group I family protein/ } \\
\text { glycosyltransferase }\end{array}$ & $\begin{array}{l}223^{S} \\
708^{M}\end{array}$ & + & + & + & + & - & - \\
\hline 44 & BRA0433/BMEII0834 & $\begin{array}{l}\text { putative glutamate-I-semialdehyde-2,I-aminomutase/ } \\
\text { glutamate-I-semialdehyde } 2, I \text {-aminomutase }\end{array}$ & 463 & + & + & + & - & - & - \\
\hline 45 & BRA0434/BMEII0833 & putative conserved hypothetical protein/hypothetical protein & 239 & + & + & + & - & - & - \\
\hline
\end{tabular}


Table 3: Detailed results for RT-PCR analysis of differentiating CDSs from Brucella species, by gene. Detailed breakdown of the transcripts detected in each differentiating sequence island of B. abortus $9-94 \mathrm{I}$, B. melitensis $16 \mathrm{M}$ and B. suis 1330 , when the cell cultures were grown at $37^{\circ} \mathrm{C}$ for 36 hours in trypticase soy broth (Difco). (Continued)

\begin{tabular}{|c|c|c|c|c|}
\hline 46 & BRA0435/BMEII0832 & $\begin{array}{l}\text { putative epimerase/dehydratase family protein/UDP-glucose } \\
\text { 4-epimerase }\end{array}$ & 642 & + \\
\hline 47 & BRA0436/BMEII083I & conserved hypothetical protein/hypothetical protein & 188 & + \\
\hline 48 & BRA0437/BMEII0830 & $\begin{array}{l}\text { putative dTDP-4-dehydrorhamnose 3,5-epimerase/dTDP-4- } \\
\text { dehydrorhamnose 3,5-epimerase dTDP-4-dehydrorhamnose } \\
\text { reductase }\end{array}$ & 285 & + \\
\hline 49 & BRA0438/BMEII0828 & $\begin{array}{l}\text { putative methyltransferase/possible s-adenosylmethionine- } \\
\text { dependent methyltransferase }\end{array}$ & 452 & + \\
\hline 50 & BRA0438/BMEII0829 & $\begin{array}{l}\text { putative methyltransferase/possible s-adenosylmethionine- } \\
\text { dependent methyltransferase }\end{array}$ & 155 & + \\
\hline 51 & BRA0439/BMEII0827 & $\begin{array}{l}\text { putative nucleotidyltransferase family protein/glucose-I- } \\
\text { phosphate cytidylyltransferase }\end{array}$ & 525 & + \\
\hline 52 & BRA0553/BMEII07I7 & putative cell wall surface protein/hemagglutinin & 421 & + \\
\hline
\end{tabular}

\begin{tabular}{|c|c|c|}
\hline 53 & BR022I/BruAbI_0216 & putative transcriptional regulator, MerR family \\
\hline 54 & BR0389/BruAbI_04I4 & hypothetical protein \\
\hline 55 & BR0390/Not annotated & hypothetical protein \\
\hline 56 & BR0588/BruAbI_0609 & putative protease \\
\hline 57 & BR0589/BruAbI_0610 & major capsid protein, HK97 family/putative protein \\
\hline 58 & BR0590/BruAbI_06II & conserved hypothetical protein \\
\hline 59 & BR059I/BruAbI_0612 & conserved hypothetical protein \\
\hline 60 & BR0592 BruAbI_0613 & hypothetical protein \\
\hline 61 & BR0593/BruAbI_0613 & conserved hypothetical protein \\
\hline 62 & BRI852/BruAbI_|831 & transcriptional regulator, $\mathrm{Cro} / \mathrm{Cl}$ family, \\
\hline 63 & BRI853/BruAbI_I832 & putative $\mathrm{AzIC}$ family protein \\
\hline
\end{tabular}

H. B. suis and B. abortus Chromosome II (SA2)

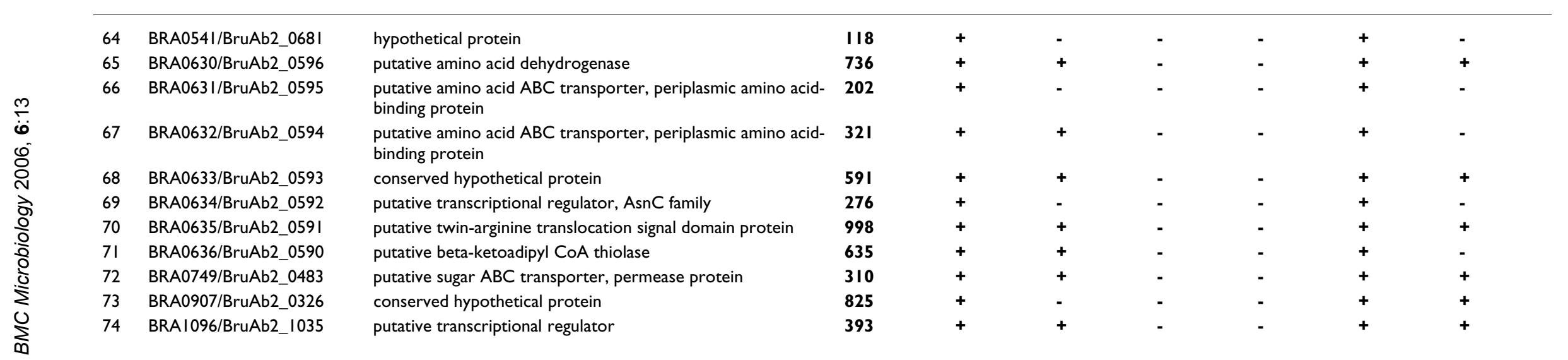


Table 3: Detailed results for RT-PCR analysis of differentiating CDSs from Brucella species, by gene. Detailed breakdown of the transcripts detected in each differentiating sequence island of B. abortus 9-94I , B. melitensis $16 \mathrm{M}$ and B. suis I330, when the cell cultures were grown at $37^{\circ} \mathrm{C}$ for 36 hours in trypticase soy broth (Difco). (Continued)

I. B. melitensis and B. abortus Chromosome I (MAI)

\begin{tabular}{|c|c|c|c|c|c|c|c|c|c|}
\hline 75 & BMEI0900/BruAbI_1088 & hypothetical protein & 212 & - & - & + & + & + & - \\
\hline 76 & BMEII674/BruAbI_0274 & hypothetical protein & 597 & - & - & + & + & + & + \\
\hline 77 & BMEII675 BruAbI_0273 & hypothetical protein & 157 & - & - & + & + & + & + \\
\hline 78 & BMEII676/BruAbI_027I & hypothetical protein & 206 & - & - & + & - & + & + \\
\hline 79 & BMEII977/BruAbI_0270 & hypothetical protein & 400 & - & - & + & + & + & + \\
\hline 80 & BMEII978/BruAbI_0269 & hypothetical protein & 192 & - & - & + & + & + & + \\
\hline 81 & BMEII979/BruAbI_0268 & hypothetical protein & 201 & - & - & + & + & + & + \\
\hline 82 & BMEII980/BruAbI_0267 & hypothetical protein & 210 & - & - & + & + & + & + \\
\hline 83 & BMEII98I/BruAbI_0266 & hypothetical protein & 358 & - & - & + & + & + & + \\
\hline 84 & BMEII982/BruAbI_0265 & hypothetical protein & 418 & - & - & + & + & + & + \\
\hline 85 & BMEII683/BruAbI_0264 & zinc-dependent metallopeptidase & 482 & - & - & + & + & + & + \\
\hline 86 & BMEII684/BruAbI_0263 & hypothetical protein & 149 & - & - & + & - & + & - \\
\hline 87 & BMEII685/BruAbI_0262 & hypothetical protein & 163 & - & - & + & - & + & - \\
\hline 88 & BMEII686/BruAbI_026I & hypothetical protein & 265 & - & - & + & + & + & + \\
\hline 89 & BMEII687/BruAbI_0260 & hypothetical protein & 167 & - & - & + & + & + & + \\
\hline 90 & BMEII688/BruAbI_0259 & hypothetical protein & 431 & - & - & + & - & + & - \\
\hline 91 & BMEII689/BruAbI_0258 & hypothetical protein & 271 & - & - & + & + & + & + \\
\hline 92 & BMEII690/BruAbI_0257 & hypothetical protein & 160 & - & - & + & - & + & + \\
\hline 93 & BMEII69I/BruAbI_0256 & hypothetical membrane spanning protein & 206 & - & - & + & - & + & - \\
\hline 94 & BMEII692/BruAbI_0255 & flagellar protein Flg & 201 & - & - & + & - & + & - \\
\hline 95 & BMEII693/BruAbI_0254 & hypothetical protein & $|5|$ & - & - & + & + & + & + \\
\hline 96 & BMEII694/BruAbI_0253 & hypothetical protein & 150 & - & - & + & - & + & + \\
\hline 97 & BMEII695/BruAbI_0252 & hypothetical protein & 239 & - & - & + & + & + & + \\
\hline 98 & BMEII696/BruAbI_025I & hypothetical membrane spanning protein & 526 & - & - & + & + & + & + \\
\hline 99 & BMEII697/BruAbI_0250 & virulence-associated protein $\mathrm{E}$ & 857 & - & - & + & + & + & + \\
\hline 100 & BMElI698/BruAbI_0249 & hypothetical protein & 245 & - & - & + & + & + & + \\
\hline 101 & BMEII699/BruAbI_0248 & hypothetical protein & 183 & - & - & + & + & + & + \\
\hline 102 & BMEII700/BruAbI_0247 & hypothetical protein & 207 & - & - & + & + & + & + \\
\hline 103 & BMEII70I/BruAbI_0246 & hypothetical protein & 221 & - & - & + & + & + & + \\
\hline 104 & BMEII702/BruAbI_0245 & transposase & 169 & - & - & + & - & + & - \\
\hline
\end{tabular}

+ Obtained RT-PCR fragment of the expected length

- No band was observed in the RT-PCR experiment

ssize of PCR fragment applies to B. suis. Msize of PCR fragment applies to B. melitensis. Asize of PCR fragment applies to B. abortus 
of bacteria. Agrobacterium contains both a virB type IV secretion system and a tra/trb bacterial conjugation system. These systems are homologous and share common ancestral origins, but they are functionally independent and physically separate $[25,26]$. Brucella spp. lack a conjugation system, which suggests that the genes in this region play a role in type IV secretion, or are part of an uncharacterized macromolecule or gene transfer system. The organization of this unique S2 region suggests a pattern of cotranscription. The short intergenic regions between the CDSs may indicate that these genes are organized as operons and are co-transcribed. In the case of the BRA0372BRA0373 operon, the start codon of BRA0373 lies within BRA0372 that may indicate a -1 or -2 frame shift mechanism for transcription of BRA0373. Examples of this type of gene/operon organization have primarily been identified in viruses $[22,27]$. It has also been identified in prokaryotes [28], although in some cases it can be an artifact of annotation error [29]. Additional study is needed to confirm the annotation in this case. Type III secretion systems are assembled from components of flagellar machinery [30]. Although Brucella does not normally produce flagella, our analysis reveals a flagellar gene (FlgJ BMEI1692) present in differentiating region MA1. This gene is on Chromosome I, instead of within one of three flagellar gene clusters on Chromosome II. It is also more than twice ( $640 \mathrm{aa}$ ) the normal size ( $313 \mathrm{aa}$ ) for this protein. In B. melitensis, all the structural genes for flagellum formation are present but genes for the chemotactic receptors or transducers are absent [31]. Based on the presence of several flagellar genes and a homologue of the LcrD virulence superfamily in $B$. abortus, it has been suggested that Brucella has the potential for motility and type III secretion [32]. However, a recent study did not detect transcription by RT-PCR in B. melitensis grown in Albimi broth of four flagellar genes $(f l h B, f l h P, f l i R, f l i F)$ present in B. suis, B. abortus, and B. ovis [33]. Our RT-PCR results revealed no transcription of the flagellar differential gene flgJ in Brucella grown in trypticase soy broth. Transcription was detected in ten genes within the same region MA1 that are defined as hypothetical proteins [31]. Recent studies suggest that a flagellar gene promoter $(f l i F)$ is induced when B. suis is replicating in macrophages; additional studies on flagellar gene expression have been performed [34,35]. It appears that at least B. melitensis can produce flagella transiently in-vitro in pure culture [35] and fla genes are necessary for chronic infection in mice [34]. Thus it is likely that flagellar gene expression occurs when Brucella is replicating in an intracellular environment such as macrophages.

\section{Site-specific recombinases}

An apparent recombinase homologue (BMEI1661) was identified as the sole unique gene for B. melitensis, and our RT-PCR results indicated that it is transcribed. There are two resolvase family genes (BME1661/BMEI0902) in the B. melitensis annotation for Chromosome I located in opposite orientations. These two genes share homology over a 180 bp consensus sequence. However, one putative recombinase (BMEI1661) is much larger than the other (747 bp vs. 231 bp). They may be considered paralogous, but BME1661 contains more than 500 bp not present in any other species. In the $B$. suis annotation, there are two almost identical recombinases of equal size (617 bp) present, in opposite orientations. These only have small matches to BME1661/BMEI0902 ( $40 \mathrm{bp}$ ). However, both $B$. abortus and B. suis contain 2 copies of $\sim 180 \mathrm{bp}$ homologous to BME1661/BMEI0902, mostly within intergenic sequence. Overall, a 180 bp consensus is present in two copies in all three species, but $\sim 500 \mathrm{bp}$ of the BMEI1661 gene in B. melitensis is unique to this species. Site-specific recombination has been shown to be involved with acquisition of drug resistance genes and alteration of gene expression [36], suggesting that this unique gene may play a role in virulence.

\section{Evolutionary implications}

Our analysis reinforces the view that the brucellae are highly similar - much more identical to each other than are other groups of closely related bacteria. It has been suggested that the low rate of genetic exchange between Brucella spp. and other species is due to their niches within cells as intracellular parasites [37]. However, several multi-gene differentiating islands identified in our comparison (Table 2) contain atypical G+C contents that is consistent with gene acquisition via horizontal transfer. Island MA1 exhibits a $\mathrm{G}+\mathrm{C}$ content of $52 \%$ and contains a putative phage integrase family transposase at the end of the gene cluster in both $B$. abortus and B. melitensis. Escherichia coli has a $\mathrm{G}+\mathrm{C}$ content of $51.4 \%$, and has been demonstrated to transfer a broad host range plasmid to Brucella under laboratory conditions [38]. Other islands have base compositions close to the average Brucella $\mathrm{G}+\mathrm{C}$ content. Island SM2 exhibits a G+C content of $58 \%$ in both $B$. melitensis and B. suis. The presence of phage genes suggests that lysogenic conversion may have occurred [39]. The island S2 that is unique to B. suis and containing $5 \mathrm{tra} / \mathrm{trb}$ genes has a $\mathrm{G}+\mathrm{C}$ content of $55.6 \%$ and is flanked by a phage integrase homologue. Two phage gene homologues (a HK97 family phage major capsid protein and putative phage head-tail adaptor) are present within island SA1 and two phage gene homologues (a HK97 family portal protein and a phage terminase subunit) flank the island. Island SA2 contains a phage minor tail protein L homologue. This evidence is consistent with phage-mediated transduction and suggests that phages may have helped the brucellae adapt to their intracellular niches. 


\section{RT-PCR analysis of differentiating regions}

Reverse transcription (RT-PCR) experiments were performed for all of the predicted coding sequences from the differentiating regions of $B$. suis, B. melitensis and B. abortus to determine whether they are transcribed in the species-specific pattern expected. When no amplicon was observed by RT-PCR, regular PCR reactions were performed to confirm the presence of differentiating sequences in genomic DNA. A total of 105 primer pairs were designed, for RT-PCR reactions targeting a total of 102 genes. Three of these were partial differentials homologs that appeared to have significant insertions in one species relative to another in which a unique primer or probe could be placed to distinguish among species and more than one primer pair was used in some of these cases.

Figure 1 is a Venn diagram of gene content in the three species. The separate sections of the figure show (A) the number of differentiating genes identified by sequence comparison and (B) confirmed in the genome sequence by PCR, and (C) transcribed in vitro, as detected by RTPCR. The smaller number of differentiating features in Figure $1 \mathrm{C}$ relative to Figure $1 \mathrm{~B}$ signifies only that some genes which we identified as differentiating features were not transcribed under the conditions of this experiment in vitro and in late log phase.

Table 2 summarizes transcripts detected for genes in each differentiating sequence island, and Table 3 shows details of predicted vs. observed RT-PCR results for each differential gene when laboratory strains of $B$. suis, B. melitensis, and $B$. abortus were probed. The RT-PCR results agreed with the results of the comparative analysis. PCR amplification of the genomic DNA confirmed the presence of the DNA segment in all cases where transcription was not detected. No unexplained transcription was detected in any case where we had predicted that the gene probed would be absent. Further work will be required to determine if differentiating genes are transcribed in the intracellular environment, e.g. the macrophage, and what effect their transcription has on the ability of the Brucella to replicate inside macrophages.

\section{Differential targets identify variant strains}

PCR and RT-PCR assays for predicted differential genes in the sequenced Brucella biovars showed that these differentials do occur in the predicted patterns. They can be used to discriminate genomic DNA from isolates of the three sequenced strains, although not all of the differentials are expressed in the late log phase. To test whether the differential sequences would be useful distinguishing the sequenced strains among a larger field of Brucella biovars we assayed 18 biovars using 24 of the 102 primer pairs.
We found that ten of the PCR primer pairs tested could provide information about strain identification when other biovars were considered. The PCR results are summarized in a graphical panel on Figure 2, and the primer sequences and amplicon sizes are provided in Table 4 . The presence of an amplicon from primer pair 6 is uniquely characteristic of the B. abortus strains [16]. This primer pair was screened against the entire GenBank Database and turned to be highly $B$. abortus specific. The presence of amplicons from pairs 2, 3 and 4 is characteristic of all $B$. suis strains except 513 . These sequences are also present in $B$. canis; additional identifying information is provided by the variable region amplified by probe pair one, as described below. Primer pair 5 was originally selected to identify B. melitensis, but was found to occur in some $B$. suis strains. However, primer pair 8 was able to amplify a 162 bp unique fragment in B. melitensis. Primer pair 1, which was expected to amplify a unique region in $B$. suis 1330 , produced a single band of varying size in every one of the 18 Brucella biovars. This polymorphic region encoding for an immunoglobulin-binding protein has a potential diagnostic application.

The patterns we observed by PCR screening several Brucella biovars can be used in a simple sequence of PCR assays, which differentiates between the classical Brucella strains (Figure 3). The assay starts with an unknown bacterial culture, which is tested with a genus specific primer pair capable to amplify a DNA fragment from any bacterial strain of genus Brucella. The primer pair 6 is highly specific to $B$. abortus and amplifies a single band in the seven biovars that were tested. If the primer pair 6 fails to produce a fragment, the bacterial culture that we test belongs to B. canis, B. melitensis, B. neotomae, B. ovis or B. suis. The PCR primer pair 8 helps to rule out two of the Brucella species by giving a substantially shorter fragment in all three $B$. melitensis biovars, and no amplicon in $B$. ovis 1155. Primer pair 13 (5'-ACC TCG GCA TGT AAC TCA GG-3' and 5'-ACC CTC CAC ACC AAT AGA CG-3') separates $B$. neotomae $5 \mathrm{~K} 33$. The next step in the diagnostic assay is to separate $B$. canis from B. suis. Although computational analysis identified the presence of large unique islands in Brucella suis 1330, the PCR results revealed that these islands are absent from B. suis 513 and found in the evolutionary related $B$. canis RM and also $B$. neotomae $5 \mathrm{~K} 33$ biovars. Use of the primer pair 11 (5'-TCG GCC TGT GGA TCT ATT TC-3' and 5'-TTC CAC TTG CGT CAC TGT TC-3') can separate most of the B. suis biovars, but an additional PCR with the primer pair 12 (5'-TTG TTG GAA ACG GCT TTG ATA TCC AC-3' and 5'-GAA AGT ACC CAC CCT CGG AAA ACT CC-3') is necessary to separate B. suis 40 from $B$. canis RM. At every identification step additional PCR reactions may be set up to confirm the Brucella species identity. The same differential regions can be used as the discriminatory features on a diagnostic microarray. 


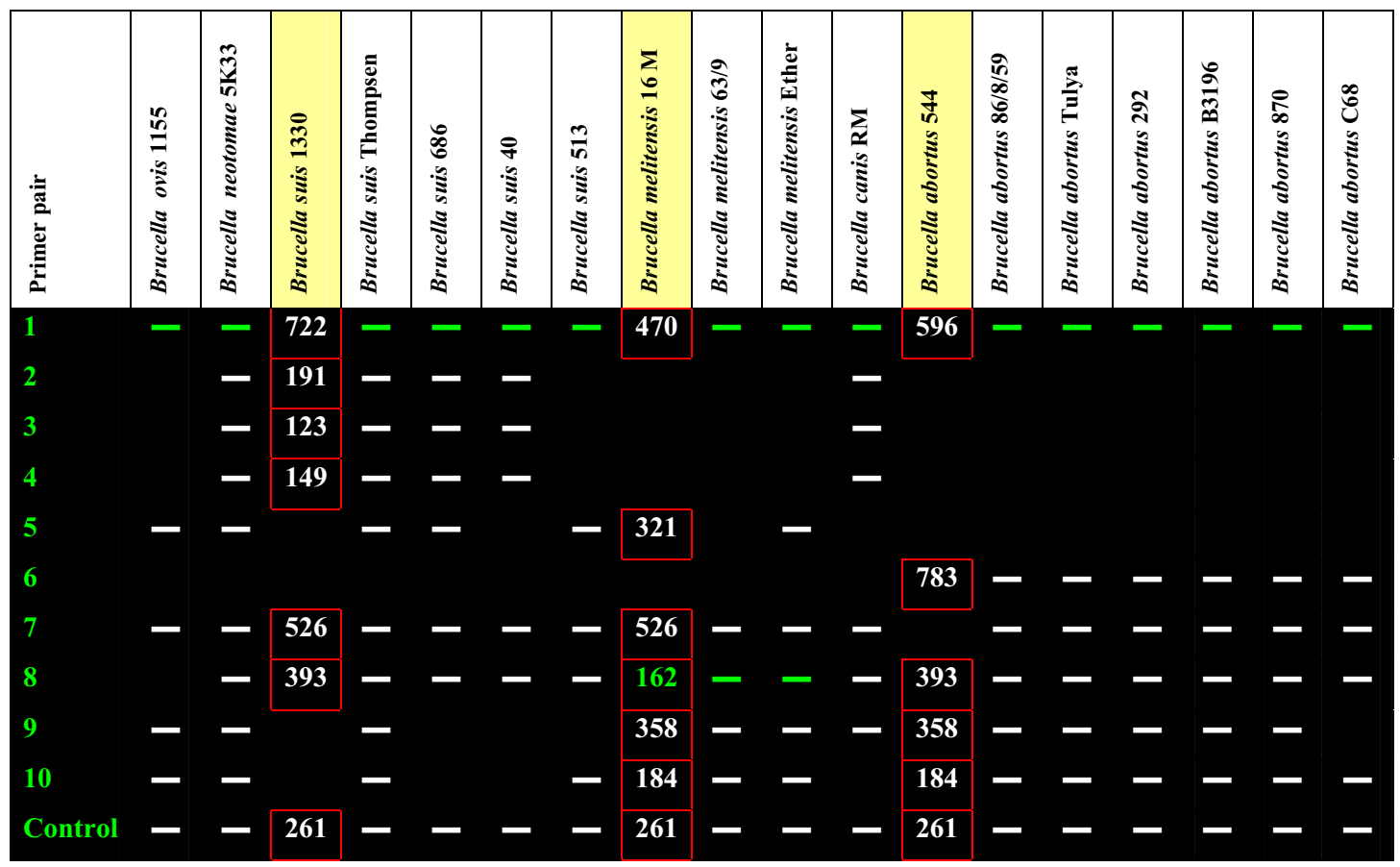

\section{Figure 2}

Graphical panel of PCR results in 18 Brucella biovars. The panel represents the patterns observed when PCR screening the differential regions across the 18 classical Brucella biovars and provides the values for the expected amplicon sizes. * The PCR was performed on extracted genomic DNA, rather than whole cells; green color shows size variability; red boundary indicates expected PCR amplification.

The primers used in this assay have been screened against all sequences currently present in GenBank. The primer pairs 5, 6, 9 and Control revealed significant full length matches at the nucleotide sequence level only to Brucella spp., when compared to the complete GenBank database. Primer pairs designed for these sequences were also found to be unique when compared to the complete GenBank database with BLASTn in short nearly exact match mode. Primer pairs were considered unique if both of the primers in a pair did not have a short nearly exact match hit in the same genome, or, if both did have a short hit in the same genome, the predicted amplicon was longer than $100000 \mathrm{bp}$ or the primer sequence hits were shorter than $14 / 20$ bp. We determined, using Hyther [40-42], that duplexes of $14 \mathrm{nt}$ and below had melting temperatures below the annealing temperature used in the experiment. Primer pairs described as unique to Brucella spp. meet these criteria and, therefore, may be useful to verify the presence of Brucella specific DNA even in the presence of the host DNA.

\section{Conclusion}

Differentiating genes identified in a comprehensive whole-genome comparison among sequenced Brucella biovars have been used successfully as targets to discriminate among Brucella strains using a small number of strategically selected PCR assays. The successful differentiating targets have been placed as features on a discriminatory synthetic 70 mer oligonucleotide array for diagnosis of Brucella infections, as well as a more comprehensive Brucella array that will be used to examine differential gene expression during host-pathogen interactions. With these experiments, we hope to determine whether differences in virulence or host preferences between $\mathrm{Bru}$ cella spp. are due to unique genes or differences in transcription and expression. The information we can obtain from differential expression studies will complement recent research in comparative proteomics of Brucella $[43,44]$. None of the differentiating genes for $B$. melitensis that we identified have yet been detected in the proteome in vitro; however, the above proteomics study resulted in annotation of only $6 \%$ of the predicted genes in $B$. melitensis. We anticipate that the answers to questions about host preference and virulence will lie in the results obtained from a combination of microarray and functional analyses of mutant strains suggested by genomic analysis and global gene expression approaches. 
Table 4: Primer pairs used for PCR amplification of unique and differential regions in I 8 Brucella biovars. Sequences of primer pairs, which where use to PCR amplify several differential genes across the 18 Brucella biovars along with the expected amplicon size and predicted gene function.

\begin{tabular}{|c|c|c|c|c|c|}
\hline \multirow[t]{2}{*}{ Primer pair number } & \multirow[t]{2}{*}{ Forward primer ... Reverse primer } & \multicolumn{3}{|c|}{ ORF name Amplicon size, bp } & \multirow[t]{2}{*}{ Gene function } \\
\hline & & B. abortus & B. melitensis & B. suis & \\
\hline $\mathbf{I}$ & TGATAGCGCCAGACAACAAC ... TGTGCCAGCTTCGTTGTAAG & BruAbI_I825 596 & BMEI0205 470 & BRI846 722 & Immunoglobulin-binding protein EIBE \\
\hline 2 & AAATGTCAATCTGGGCTTCG ... TATTGAAGAACTGCGCAACG & & & BRA0378 I9| & Hypothetical protein \\
\hline 3 & $\begin{array}{l}\text { ATTTATGTCCGTGAACTGTCCGTC ... } \\
\text { TTGTCCGCAAAAAGTATCAAAACG }\end{array}$ & & & BRA0369 I23 & Hypothetical protein \\
\hline 4 & AACTGCTGGAGATGAATCCG ... GAATGTTTGCACGCATCAAT & & & BRA0363 I49 & DNA-binding protein \\
\hline 5 & CTTTACGCCCGTGTATCGAC ... CATGGGGTCCTGTGTTGAG & & BMEII66I 321 & & Recombinase \\
\hline 6 & TGCAGCTCACGGATAATTTG ... ACACCTTGTCCACGCTCAC & BruAb2_0168 783 & & & Outermembrane transporter \\
\hline 7 & AGCTTCTGGAGGAGGTGGAT ... GTTCCGCCTTGTGTTTCTTC & & BMEII0827 526 & BRA0439 526 & Glucose-I-phosphate cytidylyltransferase \\
\hline 8 & TCTACACCACGCTGAAGTCG ... CCGAAAGCCGATAGAGTTTG & BruAb2_1035 393 & BMEII0204 I62 & BRAI096393 & Transcriptional regulator, GNTR family \\
\hline 9 & $\begin{array}{l}\text { TTGTTGGAAACGGCTTTGATATC ... } \\
\text { GAAAGTACCCACCCTCGGAAAACT }\end{array}$ & BruAbI_0266 358 & BMEII68I 358 & & Hypothetical protein \\
\hline 10 & $\begin{array}{l}\text { TCATGCTGTGCCTCCAATTCC ... } \\
\text { TTGCTGAGCAGCAGCAAGAAC }\end{array}$ & BruAbI_0248 I84 & BMEII699 I84 & & Hypothetical protein \\
\hline Control & TCAGGCGCTTATAACCGAAG ... ATCTGCGCATAGGTCTGCTT & BruAb2_0582 26I & BMEII0637 26I & BRA0644 26I & $\begin{array}{l}\text { pcaC 4-carboxymuconolactone } \\
\text { decarboxylase }\end{array}$ \\
\hline
\end{tabular}




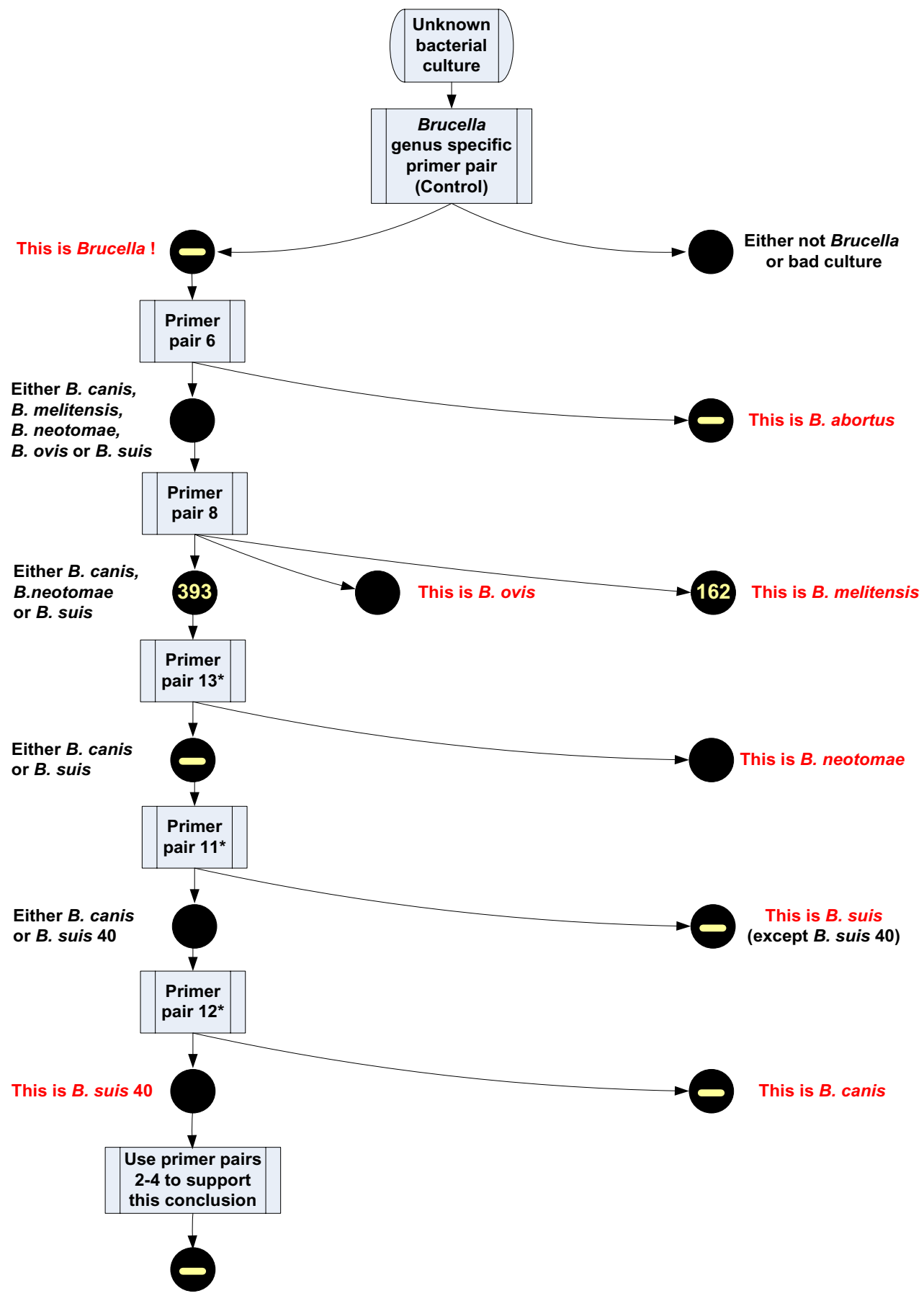

\section{Figure 3}

PCR assay which differentiates between the Brucella strains. PCR assay sequence which differentiates between classical Brucella biovars based on the patterns observed by PCR screening several Brucella biovars. * The primer pair sequences are embedded in the text. 


\section{Methods}

\section{Genome sequence data and annotation}

The B. abortus genome has been recently completely sequenced and annotated using Artemis releases 4 and 5 this year [16]. As of today, the complete, annotated genome sequences of $B$. abortus [GenBank: $\underline{\text { AE017223 }}$ GenBank:AE017224], B. melitensis [GenBank:AE008917,

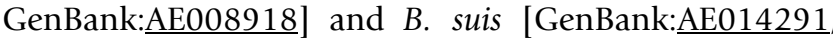
GenBank:AE014292] are available in GenBank. The genome of $B$. suis was sequenced at TIGR, and annotated using their standard procedures [14]. B. melitensis has been annotated [15] using the ERGO bioinformatics suite. However, at the time this comparison was performed, a complete annotation had not been published for $B$. abortus. Draft $B$. abortus sequence and preliminary annotations were used to represent $B$. abortus in the threeway comparison, along with over 2,000 nucleotide sequence records for $B$. abortus that are available in GenBank. We used annotated coding regions from the published sequences of $B$. melitensis and $B$. suis as the basis for protein-to-protein comparisons.

\section{Whole genome sequence comparison}

Pairwise whole genome alignments for each combination of genomes were performed using MUMmer (v. 2.1) [45]. This analysis facilitates identification of regions of nonidentity and single nucleotide polymorphisms between pairs of genomes with high sequence similarity.

\section{Sequence similarity comparison}

Sequence based local alignments were performed using standalone BLAST [46]. A two-stage process using two BLAST programs (tblastx, blastn) was used to define regions of sequence match between genomes. Predicted coding sequences in each genome were translated and compared to each other. Protein sequences were also compared to six-frame-translated genomic sequence to detect homologies that lay outside annotated gene boundaries. In the case of $B$. abortus, no annotation was available at the time of the comparison, and this process was necessary to detect putative gene homologs. Translated genome sequences of $B$. melitensis and $B$. suis were also compared to predicted proteins from other published sequences, in order to detect possible gene homologs which may not have been identified in the published annotations.

BLAST was run for each unique pairing of the three genomes. An e-value cutoff of 0.005 was used for comparisons, and the BLOSUM62 scoring matrix was used for protein-sequence-based comparisons. Genes identified in one genome, for which there were no significant matches either in coding sequence (CDS) or genomic DNA of another, were considered absent in the second genome. We observed in the genomes of these three Brucella spp. that either gene homologs existed, and had greater than $90 \%$ sequence identity, or that no apparent homolog existed; thus criteria for presence or absence of a gene were simple to establish. Differentiating genes were defined as genes for which we found no significant homology in one or both of the other genomes. A small number of gene pairs identified as matches, but having less than $80 \%$ sequence coverage of one or the other homolog, were examined more closely and classified as secondary discriminating features. Partial coverage high-scoring pairs (HSPs) for differentials were examined to determine if they could be combined to make a single match to meet our coverage cutoffs.

As an additional test of uniqueness, primer pairs designed for each of the differentiating sequences were used to query the complete GenBank database in short nearly exact match mode, to identify potential annealing sites not detected in the standard BLASTn search.

\section{PCR and RT-PCR protocols}

$B$. suis, $B$. melitensis and $B$. abortus cultures were grown at $37^{\circ} \mathrm{C}$ for 36 hours in trypticase soy broth (Difco) and harvested at an $\mathrm{OD}_{550}=0.8$. The culture was quickly harvested by centrifugation and re-suspended in TE/Citrate/ zwittergent 3-14/lysozyme lysing buffer [47]. RNA was extracted using an RNA extraction kit (Qiagen). RNA was quantified by spectrophotometric analysis. Residual genomic DNA contamination was eliminated by treatment with 5 units of DNAse1 (TaKaRa) for 1 hour at room temperature.

Primers were designed using the Primer3 software [48] with a melting temperature of $60^{\circ} \mathrm{C}, \mathrm{G}+\mathrm{C}$ content of $50 \%$ and primer length of close to $20 \mathrm{bp}$ using default values for the rest of the parameters. Our primers were determined using Nucleic Acid Quikfold (MFold version 3.1 and the SantaLucia free energy parameters for DNA) to have $\mathrm{a} \mathrm{T}_{\mathrm{m}}$ of secondary structure formation less than $40^{\circ} \mathrm{C}$, and the 2-State Hybridization Server for DNADNA-hybrid formation [49] was used to verify duplex melting temperature. An existing set of $B$. suis primer pairs (courtesy of Dr. Ian Paulsen, TIGR), originally designed for a cDNA microarray experiment, contained primers that spanned some of the differential regions and were $100 \%$ identical to their target sequences in all three Brucella genomes; 22 pairs of primers from this set were used. We also used 81 additional forward or reverse primers from this set, and the primer or primers required to complete the pair in each case were designed by us, based on the B. melitensis or B. suis annotated genomic sequence as applicable in each case. Additional file 1 contains the sequences of all primer pairs that were used in the RT-PCR and PCR analysis of the differential regions. 
Reverse transcription was carried out using the Superscript first-strand synthesis system for RT-PCR (Invitrogen) following prescribed protocols. The synthesized cDNA from each Brucella species was used in a PCR reaction as the template with primers specific for each differentiating gene. Ready-to-go PCR beads (puRETaq, Amersham Biosciences) were used according to manufacturer's recommendations. Thermocycling was carried out in the gradient Mastercycler (Eppendorf). Cycling conditions were $90^{\circ} \mathrm{C}$ for 5 minutes, $90^{\circ} \mathrm{C}$ for $1 \mathrm{~min}$, for denaturation $55^{\circ} \mathrm{C}$ for 30 seconds, for annealing $72^{\circ} \mathrm{C}$ for $1 \mathrm{~min}$ extension for 45 cycles and $70^{\circ} \mathrm{C}$ for 5 minutes of final extension. The RT-PCR products were electrophoretically separated on $1.5 \%$ (TAE/TBE) agarose gels. Primers that were suspected of producing nonspecific bands were retested with a $57^{\circ} \mathrm{C}$ annealing temperature. When the expected products were longer than $1 \mathrm{~kb}$ an increased extension time of 3 minutes was used in the second round of PCR reactions, keeping all other conditions the same.

The genomic DNA for the PCR reactions was extracted using a phenol/chloroform protocol [50]. PCR reactions were performed simultaneously for all three Brucella species. The reactions were carried out in a final volume of 30 $\mu \mathrm{l}$. Sterile water $(26 \mu \mathrm{l})$ was added to the Amersham Biosciences puReTaq Ready-To-Go-PCR bead (each bead contains 2.5 units of PuReTaq DNA Polymerase) to give: 1.5 $\mathrm{mM} \mathrm{MgCl} 2,50 \mathrm{mM} \mathrm{KCl}, 10 \mathrm{mM}$ Tris-HCl, and $200 \mu \mathrm{M}$ of each dNTP. The primer and genomic DNA concentrations were $10 \mathrm{pmol}$ and $50 \mathrm{ng}$ respectively. The DNA underwent denaturation for $5 \mathrm{~min}$. at $95^{\circ} \mathrm{C}$, followed by 40 cycles consisting of $1 \mathrm{~min}$. of denaturation at $95{ }^{\circ} \mathrm{C}, 1$ min. for primer annealing at $55^{\circ} \mathrm{C}$ and $3 \mathrm{~min}$. extension time at $72^{\circ} \mathrm{C}$, and $72^{\circ} \mathrm{C}$ for $10 \mathrm{~min}$. of final extension. The PCR products were analyzed by $1 \%$ TBE agarose gel electrophoresis.

\section{PCR screening of Brucella biovars}

Eighteen designated type strains of the six classical Brucella biovars $[51,52]$ were used to check the applicability of the identified differential regions for the diagnostic testing of Brucella species. The Brucella cells were obtained from Dr. Betsy J. Bricker at USDA, Ames Iowa, and used to set up the total of over 400 PCR reactions. The cell samples assayed included: Brucella abortus (biovars 544, 86/8/59, Tulya, 292, B3196, 870 and C68), B. canis RM, B. melitensis (biovars $16 \mathrm{M}, 63 / 9$ and Ether), $B$. neotomae 5K33, $B$. ovis 1155 and B. suis (biovars 1330, Thompsen, 686, 40 and 513).

Originally, 24 primer pairs were selected to equally represent the unique and differential ORFs we identified. A Brucella genus-specific PCR primer pair was designed and used as a positive control for the PCR assay of the differentiating regions. This primer pair was screened against all sequences from all organisms currently deposited in the GenBank Database, and is expected to be extremely Brucella specific. Each set of PCR reactions also contained a no DNA contamination control. The PCR was performed on methanol killed bacterial cells, which is a commonly used diagnostic technique $[53,54]$. The cells were diluted in water down to $0.2-0.15 \mathrm{OD}_{550} \mathrm{~nm}$ the night before the PCR analysis. The PCR amplification was performed using the PCR SuperMix from Invitrogen, with $55^{\circ} \mathrm{C}$ primer annealing temperature and 1 minute elongation time. The amplification products were then separated on the $1.6 \%$ agarose gel in a sodium borate buffer.

\section{Authors' contributions}

VGR participated in the design of the study, carried out the PCR screening of Brucella biovars and drafted the manuscript. DMS performed the computational analysis and drafted the manuscript, SR performed the RT-PCR analysis of differentiating genes. SAR performed the PCR analysis of differentiating genes. YH, RL and NS helped to analyze the data and critically revised the manuscript. SMH contributed the draft genome sequence of $B$. abortus and critically revised the manuscript. SMB and CJG conceived of the study, and participated in its design and coordination and helped to draft the manuscript. All authors read and approved the final manuscript.

\section{Additional material}

\section{Additional file 1}

Primer sequences for amplification of the differential regions in Brucella. The additional file is a table in Microsoft *. doc format containing the sequences of all primer pairs that were used in the RT-PCR and PCR analysis of Brucella differential regions.

Click here for file

[http://www.biomedcentral.com/content/supplementary/14712180-6-13-S1.doc]

\section{Acknowledgements}

We are grateful to Dr. lan Paulsen at the Institute for Genomic Research for supplying PCR primers for the $B$. suis genome. Portions of this study were funded by Dr. James Blair, Associate Provost for Interdisciplinary Research and Dr. Gerhardt Schurig, Director of the Institute for Biomedical Sciences and Public Health at VA Tech and Cooperative Agreement No. 58-3625-2-142 from the USDA to Dr. Stephen M. Boyle. We are especially grateful to Dr. Betsy Bricker of the National Animal Disease Center (Ames, lowa) for generously supplying the methanol killed Brucella biovars, and Nancy Tenpenny for extraction of B. abortus 544 genomic DNA and its PCR testing. Dr. Bruno W. S. Sobral, Director of the Virginia Bioinformatics Institute, provided support for the participation of Dr. R. Lathigra and Dr. O. He.

\section{References}

I. Boschiroli ML, Foulongne V, O'Callaghan D: Brucellosis: a worldwide zoonosis. Curr Opin Microbiol 200I, 4(I):58-64.

2. CDC: CDC-PHEPR Biological Diseases/Agents. CDC; 2003. 
3. Verger JM, Grimont F, Grimont PA, Grayon M: Brucella, a monospecific genus as shown by deoxyribonucleic acid hybridization. Int J Syst Bacteriol 1985, 35:292-295.

4. Verger JM, Grimont F, Grimont PA, Grayon M: Taxonomy of the genus Brucella. Ann Inst Pasteur Microbiol 1987, I38(2):235-238.

5. Moreno E, Cloeckaert A, Moriyon I: Brucella evolution and taxonomy. Vet Microbiol 2002, 90( I-4):209-227.

6. Pizarro-Cerda J, Moreno E, Sanguedolce V, Mege JL, Gorvel JP: Virulent Brucella abortus prevents lysosome fusion and is distributed within autophagosome-like compartments. Infect Immun 1998, 66(5):2387-2392.

7. Arenas GN, Staskevich AS, Aballay A, Mayorga LS: Intracellular trafficking of Brucella abortus in $\mathbf{J 7 7 4}$ macrophages. Infect Immun 2000, 68(7):4255-4263.

8. Pizarro-Cerda J, Moreno E, Gorvel JP: Invasion and intracellular trafficking of Brucella abortus in nonphagocytic cells. Microbes Infect 2000, 2(7):829-835.

9. Anderson TD, Cheville NF: Ultrastructural morphometric analysis of Brucella abortus-infected trophoblasts in experimental placentitis. Bacterial replication occurs in rough endoplasmic reticulum. Am J Pathol I986, I24(2):226-237.

10. Detilleux PG, Deyoe BL, Cheville NF: Entry and intracellular localization of Brucella spp. in Vero cells: fluorescence and electron microscopy. Vet Pathol 1990, 27(5):317-328.

II. Watarai M, Makino S, Fujii Y, Okamoto K, Shirahata T: Modulation of Brucella-induced macropinocytosis by lipid rafts mediates intracellular replication. Cell Microbiol 2002, 4(6):34|-355.

12. Caron E, Liautard JP, Kohler S: Differentiated U937 cells exhibit increased bactericidal activity upon LPS activation and discriminate between virulent and avirulent Listeria and Brucella species. J Leukoc Biol 1994, 56(2): I74-I8I.

13. Fountain MW, Weiss SJ, Fountain AG, Shen A, Lenk RP: Treatment of Brucella canis and Brucella abortus in vitro and in vivo by stable plurilamellar vesicle-encapsulated aminoglycosides. I Infect Dis 1985, 152(3):529-535.

14. Paulsen IT, Seshadri R, Nelson KE, Eisen JA, Heidelberg JF, Read TD, Dodson RJ, Umayam L, Brinkac LM, Beanan MJ, Daugherty SC, Deboy RT, Durkin AS, Kolonay JF, Madupu R, Nelson WC, Ayodeji B, Kraul M, Shetty J, Malek J, Van Aken SE, Riedmuller S, Tettelin H, Gill SR, White O, Salzberg SL, Hoover DL, Lindler LE, Halling SM, Boyle SM, Fraser CM: The Brucella suis genome reveals fundamental similarities between animal and plant pathogens and symbionts. Proc Natl Acad Sci U S A 2002, 99(20): I3| 48-13। 53.

15. DelVecchio VG, Kapatral V, Redkar RJ, Patra G, Mujer C, Los T, Ivanova N, Anderson I, Bhattacharyya A, Lykidis A, Reznik G, Jablonski L, Larsen N, D'Souza M, Bernal A, Mazur M, Goltsman E, Selkov E, Elzer PH, Hagius S, O'Callaghan D, Letesson J], Haselkorn R, Kyrpides $\mathrm{N}$, Overbeek $\mathrm{R}$ : The genome sequence of the facultative intracellular pathogen Brucella melitensis. Proc Natl Acad Sci U S A 2002, 99 (I):443-448.

16. Halling SM, Peterson-Burch BD, Bricker BJ, Zuerner RL, Qing Z, Li LL, Kapur V, Alt DP, Olsen SC: Completion of the genome sequence of Brucella abortus and comparison to the highly similar genomes of Brucella melitensis and Brucella suis. Bacteriol 2005, I87(8):27। 5-2726.

17. Rajashekara G, Glasner JD, Glover DA, Splitter GA: Comparative whole-genome hybridization reveals genomic islands in Brucella species. J Bacteriol 2004, I 86( I 5):5040-505 I.

18. Vizcaino N, Cloeckaert A, Zygmunt MS, Fernandez-Lago L: Characterization of a Brucella species 25-kilobase DNA fragment deleted from Brucella abortus reveals a large gene cluster related to the synthesis of a polysaccharide. Infect Immun 200I, 69(II):6738-6748.

19. Timoney JF, Gillespie JH, Scott FW, Barlow JE: Hagan and Bruner's Microbiology of Infectious Diseases of Domestic Animals. 8th edition. Ithaca, Comstock Publishing Associates; 1988

20. Mistry D, Stockley RA: IgAI protease. Int / Biochem Cell Biol 2005.

21. Fernandez-Prada CM, Zelazowska EB, Nikolich M, Hadfield TL, Roop RM, Robertson GL, Hoover DL: Interactions between Brucella melitensis and human phagocytes: bacterial surface 0 Polysaccharide inhibits phagocytosis, bacterial killing, and subsequent host cell apoptosis. Infect Immun 2003, $71(4): 2110-2119$

22. van Eyll $O$, Michiels T: Non-AUG-initiated internal translation of the L* protein of Theiler's virus and importance of this protein for viral persistence. J Virol 2002, 76(21):10665-10673.
23. Haase J, Lurz R, Grahn AM, Bamford DH, Lanka E: Bacterial conjugation mediated by plasmid RP4: RSFI0IO mobilization, donor-specific phage propagation, and pilus production require the same Tra2 core components of a proposed DNA transport complex. J Bacteriol 1995, I77( 16):4779-479|

24. Grahn AM, Haase J, Lanka E, Bamford DH: Assembly of a functional phage PRD I receptor depends on I I genes of the IncP plasmid mating pair formation complex. J Bacteriol 1997, I 79( I5):4733-4740.

25. Alt-Morbe J, Stryker JL, Fuqua C, Li PL, Farrand SK, Winans SC: The conjugal transfer system of Agrobacterium tumefaciens octopine-type $\mathrm{Ti}$ plasmids is closely related to the transfer system of an IncP plasmid and distantly related to Ti plasmid vir genes. J Bacteriol 1996, I 78( I4):4248-4257.

26. Cook DM, Li PL, Ruchaud F, Padden S, Farrand SK: Ti plasmid conjugation is independent of vir: reconstitution of the tra functions from pTiC58 as a binary system. J Bacteriol 1997, I79(4): | 29|-|297.

27. Choi J, $\mathrm{Xu} \mathrm{Z,} \mathrm{Ou} \mathrm{JH:} \mathrm{Triple} \mathrm{decoding} \mathrm{of} \mathrm{hepatitis} \mathrm{C} \mathrm{virus} \mathrm{RNA}$ by programmed translational frameshifting. Mol Cell Biol 2003. 23(5): | $489-1497$

28. Rogozin IB, Spiridonov AN, Sorokin AV, Wolf YI, Jordan IK, Tatusov RL, Koonin EV: Purifying and directional selection in overlapping prokaryotic genes. Trends Genet 2002, I 8(5):228-232.

29. Szymanski M, Barciszewski J: Lessons from sequenced genomes. Overlapping genes in Methanococcus jannaschii? IUBMB Life 2000, 49(2): $12 \mid-123$.

30. Christie PJ: Type IV secretion: intercellular transfer of macromolecules by systems ancestrally related to conjugation machines. Mol Microbiol 200 I, 40(2):294-305.

3I. Letesson I], Lestrate P, Delrue RM, Danese I, Bellefontaine F, Fretin D, Taminiau B, Tibor A, Dricot A, Deschamps C, Haine V, Leonard S, Laurent T, Mertens P, Vandenhaute J, De Bolle X: Fun stories about Brucella: the "furtive nasty bug". Vet Microbiol 2002, 90(I4):3 I 7-328.

32. Halling SM: On the presence and organization of open reading frames of the nonmotile pathogen Brucella abortus similar to class II, III, and IV flagellar genes and to LcrD virulence superfamily. Microb Comp Genomics 1998, 3(I):21-29.

33. Abdallah Al, Commander NJ, Woodward MJ, Spencer S, Hart CA Winstanley C: Type III secretion homologs are present in Brucella melitensis, B. ovis, and B. suis biovars I, 2, and 3. Curr Microbiol 2003, 46(4):24I-245.

34. Delrue RM, Deschamps C, Leonard S, Nijskens C, Danese I, Schaus JM, Bonnot S, Ferooz J, Tibor A, De Bolle X, Letesson J]: A quorumsensing regulator controls expression of both the type IV secretion system and the flagellar apparatus of Brucella melitensis. Cell Microbiol 2005, 7(8): | I5I-I I6I.

35. Fretin D, Fauconnier A, Kohler S, Halling S, Leonard S, Nijskens C, Ferooz J, Lestrate P, Delrue RM, Danese I, Vandenhaute J, Tibor A, DeBolle $X$, Letesson JJ: The sheathed flagellum of Brucella melitensis is involved in persistence in a murine model of infection. Cell Microbiol 2005, 7(5):687-698.

36. Grindley ND: Site-specific recombination: synapsis and strand exchange revealed. Curr Biol I997, 7(10):R608-I2

37. Boschiroli ML, Ouahrani-Bettache S, Foulongne V, Michaux-Charachon S, Bourg G, Allardet-Servent A, Cazevieille C, Liautard JP, Ramuz $M$, O'Callaghan D: The Brucella suis virB operon is induced intracellularly in macrophages. Proc Natl Acad Sci U S A 2002, 99(3): 1544-1549.

38. Verger JM, Grayon M, Chaslus-Dancla E, Meurisse M, Lafont JP: Conjugative transfer and in vitro/in vivo stability of the broadhost-range IncP R75 I plasmid in Brucella spp. Plasmid 1993 , 29(2): | $42-\mid 46$.

39. Boyd EF, Brussow H: Common themes among bacteriophageencoded virulence factors and diversity among the bacteriophages involved. Trends Microbiol 2002, I ( (I I):52I-529.

40. Peyret N, SantaLucia J]: Hyther. I.0th edition. 1998 [http:// ozone2.chem.wayne.edu/Hyther/hythermenu.html].

4I. Peyret N, Seneviratne PA, Allawi HT, SantaLucia J]: Nearest-neighbor thermodynamics and NMR of DNA sequences with internal A.A, C.C, G.G, and T.T mismatches. Biochemistry 1999, 38( I 2):3468-3477.

42. SantaLucia J]: A unified view of polymer, dumbbell, and oligonucleotide DNA nearest-neighbor thermodynamics. Proc Natl Acad Sci U S A 1998, 95(4): I460-I 465. 
43. Mujer CV, Wagner MA, Eschenbrenner M, Horn T, Kraycer JA, Redkar R, Hagius S, Elzer P, Delvecchio VG: Global analysis of Brucella melitensis proteomes. Ann N Y Acad Sci 2002, 969:97-I0I.

44. Wagner MA, Eschenbrenner M, Horn TA, Kraycer JA, Mujer CV, Hagius S, Elzer P, DelVecchio VG: Global analysis of the Brucella melitensis proteome: Identification of proteins expressed in laboratory-grown culture. Proteomics 2002, 2(8):1047-1060.

45. Delcher AL, Phillippy A, Carlton J, Salzberg SL: Fast algorithms for large-scale genome alignment and comparison. Nucleic Acids Res 2002, 30(I I):2478-2483.

46. Altschul SF, Gish W, Miller W, Myers EW, Lipman DJ: Basic local alignment search tool. I Mol Biol 1990, 2 I5(3):403-4I0.

47. Halling SM, Koster NA: Use of detergent extracts of Brucella abortus RB5 I to detect serologic responses in RB5 I-vaccinated cattle. J Vet Diagn Invest 200I, I 3(5):408-4I2.

48. Rozen S, Skaletsky H: Primer3 on the WWW for general users and for biologist programmers. Methods Mol Biol 2000, I 32:365-386.

49. Zuker M: Mfold web server for nucleic acid folding and hybridization prediction. Nucleic Acids Res 2003, 31(13):3406-34I5.

50. Sambrook J, Fritsch EF, Maniatis T: Molecular cloning: A laboratory manual. New York, Cold Spring Harbor Press; 1989.

5I. Meyer ME, Morgan WJB: Designation of neotype strains and of biotype reference strains for species of the genus Brucella . In Int SystBacteriol Volume 23. , Meyer \& Shaw; 1973:135-I4I.

52. Morgan WJ, Corbel MJ: Recommendations for the description of species and biotypes of the genus Brucella. Dev Biol Stand 1976, 31:27-37.

53. Bricker BJ: Diagnostic strategies used for the identification of Brucella. Vet Microbiol 2002, 90(I-4):433-434.

54. Bricker BJ: PCR as a diagnostic tool for brucellosis. Vet Microbiol 2002, 90(I-4):435-446.

Publish with Biomed Central and every scientist can read your work free of charge

"BioMed Central will be the most significant development for disseminating the results of biomedical research in our lifetime. "

Sir Paul Nurse, Cancer Research UK

Your research papers will be:

- available free of charge to the entire biomedical community

- peer reviewed and published immediately upon acceptance

- cited in PubMed and archived on PubMed Central

- yours - you keep the copyright

Submit your manuscript here:

http://www.biomedcentral.com/info/publishing_adv.asp
BioMedcentral 